\title{
THE EFFECT OF ALCOHOL ON FEELING.
}

By A. T, SHEARMAN, M.A.

I PROPOSE in this paper to treat in detail a subject to which I briefly referred in a former contribution to this journal.* On that occasion the classification of the feelings that was adopted proved useful, and will with a slight change be here retained. That is to say, there is, in the first place, the feeling occasioned by the special forms of intellectual exercise. Then there is the highly-important coinæesthesis, or feeling produced in connection with the working of the internal organs of the body. Next may be considered the feeling attaching to persons, and especially to offspring, to mankind (regarded as a whole), and to self. On the highest level of complexity we have the asthetic, moral, and religious emotions. We shall inquire how far with regard to each of these classes the inebriate experiences change as a result of the habit that he has developed.

But with respect to the feeling that is aroused in connection with the special forms of intellectual operation, it will not be possible to go into detail. It must suffice to say that in all probability in every case the inebriate's pleasure is less on the whole than it would have been if his indulgence had not taken place, and that, though occasionally his pain may be rendered less than it would otherwise have been, this will, on the whole, be the greater as his habit increases in strength. For instance, the hallucinations of sight and of hearing, and the illusions that are so common, swell the current of pain. Again, memory is exercised with much greater difficulty-i.e., more painfully. Then, though dulness of sight and of hearing cannot always be said to produce

- Vol, i., No. 4, p. $26 \mathrm{r}$. 
positive pain, such dulness implies in many instances a significant subsidence of pleasure. And, once more, judgment being rendered less sound, the pleasure arising from grasp of truth and consistency of thought will decline. In other words, what is sometimes called the "intellectual sentiment" will undergo a change for the worse.

\section{COINESTHESIS.}

We will turn first of all, then, to the highly important subject of coinæsthesis. The pathologist describes the effect of alcohol upon the bloodvessels, the tissues, the substance of the brain, the nerve-fibres, the digestive apparatus, and so on ; for radical and continuous changes in these structures take place in the case of the man who is indulging in either small or large doses of the poison. Now, the general feeling that accompanies such physiological changes is what is known as coinæsthesis. It needs no demonstration that, as such structures change, the common feeling will be modified. At least, it is obvious when one thinks at all of the subject, but emphasis upon the point seems to have appeared for the most part in very recent publications. The alterations in the sensations of the special senses, and in the higher activities of thought, have been noticed for long. But the modifications of mind arising when there are modifications of the organism generally are none the less real. As Dr. Sullivan (and no one has brought out better than he the importance of this part of the subject) remarks, when speaking of a case of alcoholic homicide, "the psychical counterpart of the organic disorders consequent on twenty years of intoxication, the affective personality is altered, the emotional tone is depressed."* Dr. Claye Shaw also has recently, in his admirable paper before the Society, called attention to the mental change that takes place.t The old personality is, I think, seldom entirely lost, but the general tone of the individual is so altered that his behaviour and his view of life undergo significant changes.

Magnan refers to this subject when be says that in chronic alcoholism "the alcoholism has already made another person of the man," + but the full import of this statement could hardly

* Journat of Montal Science, October, Igoo.

$\dagger$ The British Journal of Inebriety, vol. iii., No. 2.

$\ddagger$ Dr. V. Magnan, "On Alcoholism: The Various Forms of Alcoholic Delirium, and their Treatment," translated by W. S. Greenfield, p. $\times 55$. 


\section{The British Journal of Inebriety}

have been grasped without the help of modern pathological and psychological researches.

The prominent element in the changed personality is not the same in all cases. In one individual there may be uppermost a suicidal, in another a homicidal, impulse; in another instance the nature may be changed into that of a miser, and so on. The processes at work, however, are fundamentally the same. There is an alteration in the coinæsthesis. The rise of special characteristics is to be explained only by a separate study of the individual's mental habits.

Without any doubt, with the change of the general feeling there is an increase of pain on the whole. Occasionally there would appear to be an augmentation of pleasure, but it is a question whether the pleasurable element is ever very clearly marked. And, indeed, in those cases where some would say that there is more pleasure, others would hold that a sort of neutral feeling is produced. Maudsley's term "agreeable excitement"* denotes as accurately as any the facts of the case; there is additional excitement, and this is pleasurable. Magnan also, when he is describing the development of the alcoholic's experience, mentions this excitement, but does not say what is the value of the feeling as regards pleasure.

The state in which pleasure appears to predominate is, as just stated, that feeling of elevation that the inebriate experiences. Such feeling is occasionally present in the first attacks of delirium, but it may also often be present where there is no subsequent delirium. The inebriate appears to become increasingly susceptible to this elevation. Whereas once a dose of alcohol would have produced slight effects upon his feeling in this respect, he comes to experience a sense of elevation almost every time he indulges. But though the occasions on which the elevation is experienced increase in number as the coinæsthesis undergoes change, it is not the case that the pleasure arising on each occasion remains the same in quantity. For the duration of the pleasure will diminish, since pains consequent upon the degeneration of the bodily organism will with ever greater force flow over the region of consciousness. Magnan notes that this exaltation is sometimes

$$
\text { * "The Pathology of Mind," p. } 194 .
$$

VOL. III. 
curiously accompanied by depression.* The inebriate represents himself to be in a very enviable position, but simultaneously declares that he is about to be plunged into misery.

Testimony as to the pains occasioned by the change in coinæsthesis is borne by most writers on the subject. Some merely remark that the psychosis thus aroused is "unpleasant," others give more precise description of the mental phenomenon. Those who attempt to describe the peculiar character of the new state emphasize the feeling of depression that arises. We have already noticed the case where exaltation and depression may be found together. Attacks of dipsomania are said to commence with sadness, moroseness, and præcordial anxiety.

This place seems to be the most suitable in which to introduce the consideration of that anæsthesia to which the coinæsthesia in certain instances gives place. The general bodily feeling is no longer either painful or pleasurable; it simply ceases to exist. Dr. Broadbent + says that in a certain form of alcoholic paralysis there is from first to last no pain. Magnan, too, declares that, in the experience of the inebriate, sensibility to pain is much diminished. This loss of qualitative distinctions in the bodily feeling, or perhaps we should say the loss of feeling itself, may be partial or total. It should be noticed also that the partial anæsthesia may or may not vary with hemiplegia; that is to say, the power of movement is sometimes, but not always, diminished in proportion as the feeling of the parts is lost.

\section{FEELING CONNECTED WITH PERSONS.}

We come now to a consideration of the feelings aroused in connection with three objects of a personal type. For the purposes of the general science of psychology the precise classification that we have adopted is not of fundamental importance, but for our special work the division is valuable. Classifications that are " artificial" are, of course, framed with a view to the elucidation of the particular subject in hand.

* Loc. cit., p. 188.

† Quoted by H. C. Bastian in "Paralyses: Cerebral, Bulbar, and Spinal," pp. 595,596 . 


\section{The British Journal of Inebriety}

\section{Feeling towards Offspring.}

There is first, then, the feeling that the inebriate holds with respect to offspring. In each species of animals it is usual to find a love manifested towards the young, and man forms no exception to the rule. One may speak of a normal amount of this emotion in each one of the various species. Now, in the case of the inebriate the amount exhibited is below the normal. It may sink slightly or conspicuously, may reach zero, may even pass below zero into hatred. Frequently the changing emotion may, through the action of certain forces, be restored to its earlier condition, and particularly is this apt to be the case with respect to the mother. So far as the father is concerned, however, it may happen that there is no recall of the earlier, and no kindling of fresh, love towards his children; his parental instinct may be annihilated. Thus alcohol has the power of changing in large numbers of persons the amount, and even character, of this feeling, that is one of the most potent, pure, and far-reaching in the universe of living things.

\section{Feeling towards Mankind.}

Passing next to the emotion aroused in connection with mankind in general, we notice that it varies in a peculiar manner in the minds of different persons. One man exhibits more, another less, love for his fellow-creatures. Of course, it is often a particular section of mankind that the individual has in view in giving expression to this feeling; but it is surprising how often we form judgments concerning the whole of mankind, and it may be safely said that each person has an habitual feeling in his thoughts about humanity. On the one extreme we have persons who "think no evil"; on the other, there are those who without haste declare all men to be liars. A man habitually leans to one or other of these estimates. He may hold neither of them in its completeness, he may even occasionally fluctuate between them; but, taking his life as a whole, or taking a considerable section of that life, it will be found that he decidedly shows preference for one of the views.

Now, how does alcohol affect this feeling? On the whole, it without doubt tends to create a dislike of humanity. In the very early stages of drunkenness there is a slight movement in

$$
\text { I6-2 }
$$


the opposite direction. The drunkard becomes jovial. This state often gives place to a maudlin condition of mind, where again mankind is regarded favourably. But subsequently the feeling changes in a marked manner and degree. There are developed sullenness, resentment, anger, and desire for revengeprobably this is the order in which these after-effects arise. The writer who lays most emphasis upon these anti-social feelings is, perhaps, Mercier. He mentions all those just stated. He also points out the fact that, though the jovial, elevated feeling is frequently found in the earlier stages of intoxication, cases are on record in which such phenomenon bas not occurred. Apparently, therefore, in these last instances the inebriate passes immediately into a state of distrust and dislike of his fellow-creatures.

This anti-social feeling is not so violent or so lasting as is the feeling that comes to attach to offspring. The latter was originally stronger and was more personal than the former. Consequently, when revulsion takes place, the extreme reached in the case of the humanistic feeling is less pronounced.

\section{Feeling toreards Self.}

In proceeding to a consideration of the emotions attaching to self it might appear that we are returning to the question of coinæsthesis. But as such is by no means the case, a few words of explanation are rendered desirable. In the discussion that has already engaged our attention, the feeling is not consciously recognised by the individual to be changing. $\mathrm{He}$ is, as it were, changed in spite of himself. But in the subject that we are about to consider, he has before his attention a more or less distinct representation of himself. As Ward would say, the objective ego is presented to the subjective ego. No doubt the genesis of the former has been largely dependent upon coinæsthesis. This may be readily granted, but in the mere statement of such a fact, we have brought before us the truth that the coinæsthesis and the presentation of self are distinct things. What change then, if any, is there in the manner in which the inebriate regards himself?

At the first blush it would appear that the individual who spends most of his time in self-indulgence would find the love of self always the uppermost emotion in his mind, and that the 
inebriate readily practises self-indulgence is well known. As Maudsley says, when speaking of the alcoholic habit that leads to insanity, "if men would be self-denying, insanity would be lessened in this generation, but still more so in the next generation "; and, again, men "will go on as before, producing insanity from lack of self-denial, and when admonished of the steep and arduous path which they should follow, will go away, like one of old, sorrowful, because they have many passions."* Souttar also refers to the "youngish men who have led idle, self-indulgent lives," and who now form the larger part of the occupants of the inebriate retreat. That this indulgence, then, exists may be readily accepted, and from its presence we may argue that, at any rate at the outset of the inebriate's experience, there is a decided love of self.

But presently a change occurs, and there is manifest a diminution of this affection. The alteration apparently takes place as the man experiences misery at the thought of his lost reputation. One of the first signs of the mental attitude that is now being assumed is found in the neglect to bestow attention upon his personal appearance. $\mathrm{He}$ then comes to manifest no wish to throw off parasitic habits. He does not hesitate to sponge upon people, or to fall into debt. Presently he begins to lose hope, perhaps declares himself as unworthy to live, and refuses to believe that henceforth anybody will trouble to take any interest in him. He now becomes possessed also of a profound fear, of which he has no control. The melancholy and terror deepen until he is habitually insane, when his suicidal attempts may be common occurrences. Self has now from being an object of love become for him an object of hatred.

\section{THE HIGHER EMOTIONS.}

On the higher levels of feeling we have to deal with the æsthetic, moral, and religious emotions. It is when we come to treat such subjects as these the fact is brought home very clearly and emphatically that, in the examination of the inebriate's psychological condition, there is no possibility whatever of relying entirely upon laboratory work. It is, of course, absurd to think of employing a machine to investigate if and how far the inebriate's

* "Responsibility in Mental Disease," pp. 286, 287. 
moral emotions are affected by his indulgence. Here general observation is practically our only guide. The reader may conceive that experiments might be devised to test augmented or diminished capacity for producing beautiful objects-the capacity for painting, sculpture, or music, for instance. But we could not test in any such way the power of originating the quality of beauty; all that we could do would be to form an estimate of the accuracy of outline, perspective, and so on. In other words, in so far as purely intellectual elements enter into these emotions, some sort of experimental tests may be applied; but then, the peculiar character attaching to works of art is not of a merely intellectual nature. There is a subtle something else, and what that is only observation and "feeling" can define. But, even supposing we were able completely to measure experimentally the inebriate's power of producing the beautiful, we should still have to rely upon mere observation to determine whether the beautiful in objects continues to call forth in his mind the same emotions that it was wont to do.

\section{The Asthetic Emotions.}

Commencing, then, with the rsthetic emotions, let us endeavour to determine how with regard to them the inebriate's active and passive attitude is modified. Without any doubt much beautiful work has been done by men who have freely indulged in alcoholic stimulants. Deeds of valour have been accomplished, and poetical flights have been achieved, that but for the indulgence would not have been attempted. Professor Clifford Allbutt appears to extol the work wrought in this way when he remarks that " the hearty Bishop of Peterborough touched a deep truth when he said he had liefer Englishmen be drunkards than slaves."* But then, such deeds of valour are frequently not of much service unless followed up by peristent effort, and the latter is apt to be precluded by the after-effects of the alcohol. And the poet who, under the influence of the poison, reaches unwonted heights, will, for hours afterwards, have to be content with a sojourn on the plain or in the valley, whereas, but for such after-effects, his flight might still have been sustained at elevations where the range of view is not to be despised. And, moreover, his constant indulgence will eventually, and all too soon, prevent any further

* Brain, vol. i., p. 68, article "On Brain Forcing," by T. Clifford Allbutt. 
flights, so that humanity will be deprived of visions that he might have portrayed during the greatest vigour of his manhood, or with the experience of his still later years. The nation, in other words, would probably be the gainer if its men of genius and its men of daring never relied upon the inspiration derived from the intoxicating cup.

In this connection it is important to touch upon the question of manners-that is to say, refined behaviour in the company of one's fellows. Writers upon alcoholism state, without hesitation, that the inebriate's manners undergo a very serious deterioration. Mercier, for instance, says that the inebriate is unfit to associate with ladies and gentlemen.* This view is undoubtedly correct. Through lack of self-control the man under the influence of alcohol may perform actions and give utterance to words that would shock any civilized society.

But when we proceed to consider the passive side of the æsthetic sentiment, the truth appears to be that the inebriate has not really lost his desire to manifest correct behaviour. Attempts at politeness are very common in his experience, and any violation of decorum occasioned by his loss of muscular control is frequently regretted by him with evident sincerity. Inebriates, in short, are not necessarily devoid of the gentlemanly spirit. As Souttar says, quoting from another writer, many of those who go into inebriate homes go in gentlemen.

And just as this sentiment is not necessarily lost, so there frequently remains a love for pictures and music, not such as minister to the lower appetites, of course, but such as help towards producing a good and noble life. Hence reformers who make use of artistic objects of this description in retreats and similar institutions are, without doubt, on the right lines. Sometimes it does certainly occur that the musician who has given the reins to his drinking propensities, attributing his downfall to the temptations of his profession, has come eventually to hate the music that he once so greatly loved. But this is a rare case, and perhaps here we ought rather to say not that he has come to dislike music, but that he dreads the vices to which sometimes those in the profession succumb. 


\section{The Moral Emotions.}

When we come to deal with the inebriate's moral character, the division of the subject that was adopted in the previous case is also of value: we may, that is to say, regard the question from the active and from the passive standpoint. From a superficial view we might be inclined to state that the inebriate shows an all-round moral degradation. But this is not entirely true.

Let us begin with the passive side. The emotions that come in for consideration under the head of morality have been divided into moral and quasi-moral. The former attach themselves to virtue and goodness, the latter to such qualities as truth-speaking, bravery, generosity, and so on. Now, so far as these qualities are viewed in the abstract, there appears to be no reason for saying that alcohol leads a man to regard them in a peculiar fashion. A drinker does not despise goodness or bravery in the abstract. If anything, he would extol these qualities with more demonstrativeness than he previously manifested. Neither does the feeling towards such qualities undergo deterioration when they are being exhibited in the lives of other people. The man, when under the influence of alcohol, will applaud the hero and the generous person just as much as at other times. It is when we begin to consider the question of the manifestation of these qualities in his own life that we observe a change in his estimate of their value. Moral or quasi-moral conduct, so far as it might be illustrated in his own life, is no longer so admired by him that he feels inclined to cultivate it.

And this leads us to the consideration of the question from the active point of view. The inebriate, during the intervals of sanity, increasingly chooses courses of conduct that are immoral. It is only during such intervals that we have a right to speak of his conduct as either moral or immoral, for when he is drunk he is insane, and is therefore not responsible for the decisions at which he arrives. These cessations, then, to do right become more frequent, until he arrives eventually at being habitually immoral.

It has been necessary to go into this matter in some detail because the views that are commonly expressed are, as a rule, too sweeping. They do not distinguish the various aspects of the question that need separate attention. Magnan, for instance, 


\section{The British Journal of Inebriety}

affirms that the moral sense of the inebriate is blunted. But what does this mean? Does it mean that the inebriate ceases to love, or ceases to perform moral acts, or both? And, if the first, does it mean that he ceases to love moral actions in the abstract or in the concrete? And, if in the concrete, is it when they are illustrated in his own life or in the lives of others? These are different questions, and they cannot be answered in such a general manner as that adopted by Magnan. Of course the word "sense" suggests that the subject is being considered from the passive point of view, and when Maudsley says that the inebriate's moral feeling is notably weakened at the earliest stage of intoxication, it is the same side of the subject that is suggested, but it is doubtful whether these writers wish their words thus to be restricted in application. Sometimes what is meant is obvious enough. When M. Jolly* emphasizes the moral treatment of the alcoholic, it is clear that there is here reference to the feeling of respect and admiration with which the moral conduct of others is still regarded by the patient. Souttar's statement that the bad character of the inebriate is a more fundamental matter than the drinking habit is undoubtedly true, but I should be inclined, in accordance with the above analysis, to add that the drink habit may intensify the badness of the character, and may render the individual less inclined to admire and cultivate virtue in his own life.

There are many forms in which immorality is expressed in the life of the inebriate. Probably the two most impressive are untruthfulness and obscenity. Mercier bears testimony to the lying propensities of the inebriate, $\uparrow$ and Wynn Westcott affirms that secret drinking is frequently denied "with lying protestations of temperance, even to one's doctor." The manifestation of obscenity is, for the most part, confined to the stages where insanity has become almost habitual, at which periods such immorality is very common.

\section{The Religious Emotions.}

It might appear that the transition from the subject that we have just discussed to a consideration of the religious sentiment is a very simple one, and to some extent this is the case. At

* Quoted by Magnan, loc. cit., pp. 98, 99.

$\dagger$ Loc. it., p. 159 . 
the same time, many men who are moral are not distinctively religious; and, on the other hand, there are some persons who, though certainly possessing much religious feeling, manifest in their conduct anything but morality.

In the latter category the inebriate may often find a place. One might have thought that an individual who is largely under the control of alcohol would be without any moral and religious feeling, and would perform no moral or religious acts. We have, however, already seen that though the inebriate's conduct is frequently, indeed generally, immoral, his feeling with regard to certain exhibitions of good conduct is not necessarily changed in a corresponding manner. And here we have to notice a similar phenomenon. Alcohol does not necessarily or usually destroy the religious sentiment when this has once been present in the mind in anything above the minimum degree.

Perhaps I may quote here one or two of the cases mentioned in a review* of my earlier article in this Journal, though, as a rule, I prefer to state in general terms the results of my observations, and to leave to the reader the task of supplying his own illustrations. The reviewer says: "Several inebriates we have known are, however, notably religious men-one a churchwarden! One very sad case of a father with frequent recurrent attacks of alcoholism affects piety, we believe, quite genuinely. $\mathrm{He}$ is a strict observer of the Sunday, and will not then allow his sons to cycle, though he occasionally himself carries on an orgie on the day of rest. Another gentleman we know of-a bad case-is a very regular attendant at Holy Communion."

It is to be noted that the modifications of the religious sentiment through the action of alcohol are in the case of women less severe than those which occur in the case of men. Without doubt normal women are more susceptible to religious impressions than are normal men, and during the alcoholized life there remains the same ratio in the two susceptibilities.

These remarks should be taken in connection with the view sometimes expressed that alcohol "lessens the closeness of the relationship between the organism and its environment." While there is such a severance in course of creation, there is not neces-

* The General Practitioner, April 30, 1904. 
sarily a loosening in the relationship between the spirit for whom the organism exists and that Spirit who is more abiding than the environment. Hence it is scientific to hold that the work of the preacher is not yet done. This individual rightly finds a place in modern life. In the performance of his duties he may touch feelings in the inebriate's mind that will lead to the formation of healthy and elevating resolutions.

I have considered it necessary to emphasize the fact that the inebriate has not necessarily lost all religious feeling. Dr. Souttar, who takes the existence of this emotion for granted, points to the interesting fact that at one time religion encouraged drinking excesses. It should, however, be observed that such functions were special occasions, and that the religions in question never recommended the habit of immoderate drinking. Generally, religion has been decidedly on the side of moderation or abstinence. It has frequently kept people sober, and, as Souttar notices, it sometimes leads inebriates deliberately to enter retreats in order to have a better chance of breaking the alcoholic habit.

It is, we may be sure, highly important to bring both moral and religious forces to bear upon the thought of the inebriate. It is these, and these only, that can produce the goodness of will, without which reform is impossible. At the present time no scientist, perhaps very few who are not scientists, would doubt that the practice of taking alcoholic drinks is, when it reaches a certain point, to be classed as a disease, and to be treated in a manner analogous to the way other diseases are treated. This side of the subject is now insisted upon with as much emphasis as was the moral and religious side fifty years ago. But it is perfectly clear that it is not of the slightest use for the medical man to deal with an alcoholic who has no intention of reforming. The medical treatment can assist men in carrying out their intention to become sober, but it cannot create the intention. At the outset, or during the course of the medical attention, what must take place is a change in the alcoholic's character. Other things in the work of reform are desirable, and in some cases necessary, but a good will is always indispensable, and nothing can produce this but forces that are moral and religious.

NoTE.-It will be seen from the last paragraph that I believe there are more methods of diminishing inebriety than those 
suggested by Dr. Archdall Reid. On a first reading of his doctrines it is sometimes supposed-and not unnaturally so-that he holds that anything in the nature of measures to be voluntarily adopted for the removal of drunkenness is useless, if not positively injurious. Such is not, however, his meaning, as he clearly points out in his paper, "The Pathology of Chronic Alcoholism: A Reply."* His view is that "we should keep the drunkard sober if possible, but in addition deter him in every way from reproducing his type."

Now, Dr. Archdall Reid right through his reasonings takes practically no account of the drinker's force of volition, but simply places the taking of alcohol in the same category as the catching of malarial fever or of pneumonia. But this is undoubtedly an erroneous way of arguing. Most drinkers can, if they will, refuse to take any more alcohol, while an Englishman on the Coast cannot refuse to catch malaria, and the West African cannot refuse to catch pneumonia in an English climate. Resolution is a creative mental force, and is sufficient to restrain any drinker whose will-power has not actually been lost. There is no need to restrict ourselves to Dr. Archdall Reid's remedies, much less to wait until Nature has killed out those persons who have a strong tendency towards taking the poison.

The weak links in Dr. Archdall Reid's reasoning are bis tenth and eleventh propositions. To attribute drinking to a susceptibility to the charm of alcohol, and to say that individuals drink in proportion to this susceptibility, is twice to commit the fallacy of non-observation. The argument omits all consideration of the existence of plurality of causes. In the first place, early drunkenness is due to many other things than this susceptibility-e.g., to thoughtlessness, to desire for sensual pleasure, to a wish to be sociable, or to a longing to escape from worry and pain. And, secondly, to say that individuals drink in proportion to the susceptibility is to omit due consideration of the force of resolution, for it is a fact, which has been witnessed on all sides, that frequently men with a strong tendency to drink and to get drunk, have, both morally and religiously, become reformed characters.

* The British Journal of Inebrietv, vol. iii., No. I. 


\section{The British Journal of Inebriety}

No doubt Dr. Archdall Reid considers that he has not omitted consideration of the further causes, since he speaks of the behaviour of men " as a rule." But the introduction of the idea of rule does not free him from fallacy. For this statement concerning the general action of men is based on the assumption that men with wills instructed and disciplined will act in the same way as did the men of the past, who were largely governed by impulse. Such a generalization is not valid. In other words, we are not restricted to the consideration of men who behave like our ancestors, but we may endeavour to influence individuals to act according to the dictates of a will that is good. 